\title{
COMPARISON BETWEEN LETROZOLE ALONE VERSUS LETROZOLE-GONADOTROPHINS COMBINATION IN VERSUS CLOMIPHENE CITRATE - GONADOTROPHINS COMBINATION IN OVARIAN INDUCTION FOR PCOS PATIENT UNDERGOING INTRAUTERINE INSEMINATION
}

\author{
By
}

\section{Ahmed El-Sayed Abd El-Maksoud, Khaled Zakaria El-Sheikha and Adel El-Sayed Ibrahim}

Department of Obstetrics and Gynecology, Faculty of Medicine, Al-Azhar University

Corresponding Author: Ahmed El-Sayed Abd El-Maksoud,

E-mail: a-abdelmaksoud22@gmail.com

\begin{abstract}
Background: Ovulatory dysfunction is a common cause of infertility and polycystic ovary syndrome (PCOS) is the main reason of this dysfunction. PCOS is the most common endocrinopathy in women of childbearing age. A combination of ovarian stimulation or superovulation with intrauterine insemination (IUI) remains an important option available to an infertility specialist and is a widely used treatment modality for a broad range of indications.
\end{abstract}

Objective: To compare between Letrozole-Gonadotrophins combination in and Clomiphene Citrate Gonadotrophins combination in ovarian induction for PCOS Patient undergoing Intrauterine Insemination.

Patients and methods: prospective chohort study was conducted in International Islamic Center for Population Study and Research, Al-Azhar University including 300 infertile women who already diagnosed as PCOS by Rotterdam 2003 Criteria. Women had been divided randomly into three equal groups: Group (A) were given clomiphene citrate $100 \mathrm{mg}$ daily starting on day 3 till 7 day of cycle plus gonadotrophins (75 IU) once daily starting from 6th day of the cycle till growing follicle reach $18 \mathrm{~mm}$, Group (B) were given letrozole $(5 \mathrm{mg} /$ day) starting on day 3 till 7 day of cycle plus gonadotrophins 75 IU once daily starting from 6th day of the cycle till growing follicle reach $18 \mathrm{~mm}$ and Group (C) were given letrozole (5mg/ day) starting on day 3 till 7 day of cycle.

Results: Women's ovulation rate in Group (A) was 78\% had ovulation while in Group (B) $80 \%$ had ovulation and $68 \%$ in group (C). There were statistically significant differences between groups. Women's pregnancy rate in Group (A) was $8 \%$ in Group (B) was $7 \%$ in group (C) was $4 \%$. There were no statistically significant differences between groups. Group A showed more multiple follicles, more OHSS and then group B and C. more cancellation rate than group B. Group B showed less in multiple follicles and less OHSS than group $\mathrm{A}$ and less in cancellation rate than group $\mathrm{A}$ and $\mathrm{C}$ better in endometrial thickness. Group C Letrozole alone more monofollicular growth, less multiple follicles, less multiple pregnancy, less OHSS and less coast. Than group A and B but had less ovulation rate and more in cancellation rate than group A and B.

Conclusion: We can offer ovulation induction and intrauterine insemination (IUI) for PCOS if first lines (lifestyle changes, pharmacotherapy (metformin, clomiphene citrate, letrozole, gonadotrophins) failed.

Keywords: Letrozole, Letrozole-Gonadotrophins Combinationin, Clomiphene, Gonadotrophins Combination, PCOS, Intrauterine Insemination 


\section{INTRODUCTION}

Polycystic ovary syndrome (PCOS) is a heterogenous condition affecting 5-10\% of women at reproductive age. It is the most common cause of anovulatory infertility, characterized by hyperandrogenism and arrested follicle development, and is frequently associated with metabolic features such as insulin resistance and obesity. The diagnosis of PCOS, based on the Rotterdam criteria, can be made when at least two of the following three main features are met: oligo-ovulation and/or anovulation, hyperandrogenism (clinical and/or biochemical), and polycystic ovarian morphology at ultrasound examination. Several approaches to ovulation induction have been proposed in women with PCOS. These approaches vary in efficacy, treatment duration, cost, and patient compliance. Management includes lifestyle changes, pharmacotherapy (metformin, clomiphene citrate, letrozole, gonadotropins, inositol), laparoscopic surgery (ovarian drilling), and assisted reproductive techniques, usually in vitro fertilization. Clinical decisions in PCOS anovulatory patients are currently supported by a recently published international evidence-based guideline provides recommendations to help clinicians in the diagnosis and management of PCOS and to guide clinical practice (Giulia and Jose, 2018).

Ovarian stimulation and IVF are considered the third-line treatment for infertile women with PCOS. IVF is especially recommended if there are additional infertility factors, such as tubal damage, advanced woman age, severe endometriosis, and male subfertility. A single embryo-transfer procedure markedly reduces the risk for multiple pregnancies, which is one of the main drawbacks of using gonadotropins (Teede et al., 2018).

IUI with or without ovarian stimulation (OS) has become a first-line treatment option for many infertile couples, worldwide. The appropriate treatment modality for couples and their clinical management through IUI or IUI/OS cycles must consider maternal and perinatal outcomes (Cohlen, et al., 2018).

Intrauterine insemination (IUI) is widely used to treat moderate male infertility and unexplained infertility. However, studies on the use of IUI in women with PCOS are limited. In addition, PCOS were included with other types of infertility (Bordewijk et al., 2017).

In PCO, when first lines failed, there is no consensus as to the optimal approach. IVF is more effective but more costly and not always available or acceptable to the patient, while ovulation induction and intrauterine insemination (IUI) is less expensive, but when ineffective delays conception. While the selection of infertility treatment is based on medical indications, factors such as patient age, patient preference, procedure risk, birth rate, insurance coverage, and cost must also be considered. As an example, we would typically offer a woman younger than age 35 ovulation induction and IUI because of the low risk of the treatment, low cost, and reasonable chance of conception. However, an identical woman may prefer to go directly to IVF to maximize her chance of a live birth despite the higher cost and invasive 
technique compared with ovulation induction and IUI (Guzick et al., 2013).

A combination of ovarian stimulation or superovulation with intrauterine insemination (IUI) remains an important option available to an infertility specialist and is a widely used treatment modality for a broad range of indications. Common indications include cervical factor, mild endometriosis, mild to moderate male factor, ovulatory dysfunction and unexplained infertility (Kamath et al., 2010).

The aim of this work was to study the effect of induction of ovulation with Letrozole alone or Letrozole and gonadotrophins or Clomiphene Citrate and gonadotrophins in patients with PCOS undergoing intrauterine insemination (IUI).

\section{PATIENTS AND METHODS}

Randomized control trial was conducted in International Islamic Center for Population Study and Research, AlAzhar University. The study was conducted on 300 infertile women who already diagnosed as PCOS by the Rotterdam Criteria (2003). At least, twelve small follicles $2-9 \mathrm{~mm}$ in at least one ovary; Symptoms or biochemical evidence of hyperandrogenism; (Hirsutism/acne or elevated serum total testosterone) and Anovulation or oligoovulation with fewer than nine menstrual periods every 12 months.

\section{Inclusion Criteria:}

Age18-35 year, normal semen analysis, normal hysterosalpingography, infertility more than two year and body mass index less than 30 .

\section{Exclusion Criteria:}

Tubal factor infertility, abnormal semen analysis, abnormal serum TSH, elevated serum PRL and history of medical disorders e.g hypertension or diabetes.

-Sampling Method: Convenience sampling method.

\section{-Sample Size:}

This sample size was calculated with confidence interval (CI) 95\% Alpha ( $\alpha$ error) 0.05 and power of the study $80 \%$.

$$
n=\left[\frac{Z_{\propto / 2}}{\mathrm{E}}\right]^{2} * \mathrm{P}(1-\mathrm{P})
$$

(Dawson and Trapp, 2004).

Where:

$$
\mathrm{n}=\text { sample size }
$$

$\mathrm{Z} \alpha / 2=1.96$ (The critical value that divides the central $95 \%$ of the $\mathrm{Z}$ distribution from the $5 \%$ in the tail)

$\mathrm{p}=$ the Prevalence of polycystic ovary syndrome among infertile women in Egypt $=13 \%($ Sanad, 2014) .

$\mathrm{E}=$ the margin of error (=width of confidence interval).

Sample size had been at least 300 patients.

All women in the study were subjected to the following:

1. Informed consent was obtained before their inclusion in the study.

2. Full History Taking: Personal history, menstrual history, obstetric history which included gravidity, parity, abortions, sexual history which included coital frequency and 
dyspareunia, past history of hypertension and family history.

3. General and gynecological examination: General examinations and Gynecological examination of the vulva, vagina, cervix, uterus and adenexa.

\section{Women had been divided randomly into three equal groups: Group (A)} were given clomiphene citrate $(100 \mathrm{mg}$ daily) starting on day 3 till 7 day of cycle, plus gonadotrophins (75 IU once daily) starting from 6th day of the cycle till growing follicle reach $18 \mathrm{~mm}$, group (B) were given letrozole ( $5 \mathrm{mg}$ / day) starting on day 3 till 7 day of cycle, plus gonadotrophins (75 IU once daily) starting from 6th day of the cycle till growing follicle reach $18 \mathrm{~mm}$ and group (C) were given letrozole $(5 \mathrm{mg}$ / day) starting on day 3 till 7 day of cycle. Regular follow up of ovulation with folliculometry by transvaginal ultrasound starting from cycle day 9 for growing of follicle until reach $18 \mathrm{~mm}$ or more. The endometrial thickness in $(\mathrm{mm})$ was measured at this time. HCG was administered when the leading follicle reached $18 \mathrm{~mm}$. or more. All groups were subjected to intrauterine insemination (IUI) 36-40 hours after hCG administration. In IUI semen was obtained by masturbation after three to five days of abstinence then preparation carried out by swim up technique then IUI was done. The patient was asked to rest for10-15 minutes following insemination. Luteal phase support for the two groups by use of progesterone (100- $200 \mathrm{mg}$.) twice daily for two weeks. Serum pregnancy test was done 2 weeks after hCG administration and if positive trans-vaginal ultrasound was done 2 weeks later to confirm clinical pregnancy.

\section{Statistical analysis of the data:}

Data were fed to the computer and analyzed using IBM SPSS software package version 20.0. (Armonk, NY: IBM Corp) Qualitative data were described using number and percent. The Kolmogorov-Smirnov test was used to verify the normality of distribution Quantitative data were described using range (minimum and maximum), mean and standard deviation. Significance of the obtained results was judged at the 5\% level. Chi-square test: for categorical variables, to compare between different groups. ANOVA test: For normally quantitative variables, to compare between more than two studied groups. Kruskal-Wallis $\mathrm{H}$ test was used for abnormally quantitative variables to compare between two studied groups.

\section{RESULTS}

Endometrial thickness at day of $\mathrm{HCG}$ in Group A ranged between 5-12 with mean \pm S.D. $8.37 \pm 1.359$, while in Group B ranged between 4-12 with mean \pm S.D. $8.64 \pm 1.474$ and in Group $\mathrm{C}$ ranged between 4-11 with mean \pm S.D. $7.83 \pm 1.640$. There was statistically significant differences between all groups and between Group $C$ and each of group $A$ and group B. Number of mature follicle in Group A ranged between 0-12 with mean \pm S.D. $3.26 \pm 2.538$ while in Group B ranged between 0-7 with mean \pm S.D. $2.10 \pm 1.168$ and in Group $\mathrm{C}$ ranged 
between 0 -2 with mean \pm S.D. $0.85 \pm 0.687$. There were statistically significant differences between all groups and between group each other (Table 1).

Table (1): Comparison between three groups as regard endometrial thickness at day of HCG and patient's Number of mature follicle

\begin{tabular}{|c|c|c|c|c|}
\hline Parameters & $\begin{array}{c}\text { Group (A) } \\
(\mathbf{n}=\mathbf{1 0 0})\end{array}$ & $\begin{array}{c}\text { Group (B) } \\
(\mathbf{n}=\mathbf{1 0 0})\end{array}$ & $\begin{array}{c}\text { Group (C) } \\
(\mathbf{n}=\mathbf{1 0 0})\end{array}$ & P Value \\
\hline \multicolumn{5}{|c|}{ Endometrial Thickness at day of HCG: } \\
\hline Min.-Max. & $5-12$ & $4-12$ & $4-11$ & \multirow{4}{*}{0.001} \\
\hline Mean \pm S.D & $8.37 \pm 1.359$ & $8.64 \pm 1.474$ & $7.83 \pm 1.640$ & \\
\hline $\mathbf{P}_{1}$ & & 0.203 & 0.011 & \\
\hline $\mathbf{P}_{2}$ & & & $<0.001$ & \\
\hline \multicolumn{5}{|c|}{ Number of mature follicle: } \\
\hline Min.-Max. & $0-12$ & $0-7$ & $0-2$ & \multirow{4}{*}{$<0.001$} \\
\hline Mean \pm S.D & $3.26 \pm 2.538$ & $2.10 \pm 1.168$ & $0.85 \pm 0.687$ & \\
\hline $\mathbf{P}_{1}$ & & $<0.001^{*}$ & $<0.001$ & \\
\hline $\mathbf{P}_{2}$ & & & $<0.001$ & \\
\hline
\end{tabular}

$P: p$ value for comparing between the three studied groups

$\mathrm{P}_{1}$ : $\mathrm{p}$ value for comparing between group $(\mathrm{A})$ and other groups

$\mathrm{P}_{2}$ : $\mathrm{p}$ value for comparing between group (B) and group (C)

Women's pregnancy rate in Group (A) showed that $8(8 \%)$ were pregnant and $92(92 \%)$ were non-pregnant while in Group (B) 7(7\%) were pregnant and 93(93\%) were non-pregnant and in group (C) $4(4 \%)$ were pregnant and 96(96\%) were non-pregnant. There were no statistically significant differences between groups. Women's Ovarian hyperstimulation syndrome in Group (A) showed that $5(5 \%)$ Ovarian hyperstimulation syndrome while in Group (B) 1(1\%) Ovarian hyperstimulation syndrome and group (C) NO Ovarian hyperstimulation syndrome. There were statistically significant differences between groups. Women's number of follicle in Group (A) showed that $16(16 \%)$ had one follicle, $35(35 \%)$ with two follicle and 49(49\%) had more than 2 follicle, while in Group (B) 30 (30\%) had one follicle, 45(45\%) with two follicle and $25(25 \%)$ had more than 2 follicle and in group (C) $83(83 \%)$ had one follicle and $17(17 \%)$ with two follicle. There were statistically significant differences between groups. Women's ovulation rate in Group (A) showed that $22(22 \%)$ had no ovulation and $78(78 \%)$ had ovulation while in Group (B) 20(20\%) had no ovulation and $80(80 \%)$ had ovulation and in group (C) 32(32\%) had no ovulation and $68(68 \%)$ had ovulation. There were statistically significant differences between groups (Table 2). 
Table (2): Comparison between three groups as regard to patient's pregnancy rate by both serum pregnancy test and confirmed by ultrasound, ovarian hyperstimulation syndrome (OHSS), number of follicle and ovulation rate

\begin{tabular}{|c|c|c|c|c|c|c|c|}
\hline \multirow{2}{*}{ Parameters } & \multicolumn{2}{|c|}{$\begin{array}{c}\text { Group (A) } \\
(n=100)\end{array}$} & \multicolumn{2}{|c|}{$\begin{array}{c}\text { Group (B) } \\
(n=100)\end{array}$} & \multicolumn{2}{|c|}{$\begin{array}{c}\text { Group }(\mathbf{C}) \\
(\mathbf{n}=\mathbf{1 0 0})\end{array}$} & \multirow{2}{*}{$\begin{array}{c}\mathbf{P} \\
\text { Value }\end{array}$} \\
\hline & No. & $\%$ & No. & $\%$ & No. & $\%$ & \\
\hline \multicolumn{8}{|l|}{ Pregnancy Rate: } \\
\hline Pregnant & 8 & 8 & 7 & 7 & 4 & 4 & \multirow{2}{*}{0.482} \\
\hline Non-Pregnant & 92 & 92 & 93 & 93 & 96 & 96 & \\
\hline \multicolumn{8}{|c|}{ Ovarian hyperstimulation syndrome: } \\
\hline No & 95 & 95 & 99 & 99 & 100 & 100 & \multirow{2}{*}{0.028} \\
\hline Yes & 5 & 5 & 1 & 1 & 0 & 0 & \\
\hline \multicolumn{8}{|c|}{ Number of Follicle: } \\
\hline One follicle & 16 & 16 & 30 & 30 & 83 & 83 & \multirow{3}{*}{$\begin{array}{c}<0.00 \\
1\end{array}$} \\
\hline Two follicles & 35 & 35 & 45 & 45 & 17 & 17 & \\
\hline$>2$ follicles & 49 & 49 & 25 & 25 & 0 & 0 & \\
\hline \multicolumn{8}{|l|}{ Ovulation rate: } \\
\hline No & 22 & 22 & 20 & 20 & 32 & 32 & \multirow{2}{*}{0.018} \\
\hline Yes & 78 & 78 & 80 & 80 & 68 & 68 & \\
\hline Total & 100 & 100 & 100 & 100 & 100 & 100 & \\
\hline
\end{tabular}

Women's Cancelation rate due to anovulation in Group (A) show that $78(78 \%)$ had ovulation and $22(22 \%)$ had cancelation due to anovulation while in Group (B) 80(80\%) had ovulation and $20(20 \%)$ had cancelation due to anovulation and in group (C) 68(68\%) had ovulation and $32(32 \%)$ had cancelation due to anovulation. There were statistically significant differences between groups. Women's cancellation rate due to anovulation in Group (A) showed that $73(73 \%)$ had no cancellation, $22(22 \%)$ had cancellation due to anovulation and 5(5\%) had cancellation due to OHSS, while in Group (B) $79(79 \%)$ had no cancellation and 20(20\%) had Cancellation due to anovulation and1 (1\%) had Cancellation due to OHSS, while in group (C) 68(68\%) had no cancellation and $32(32 \%)$ had cancellation due to anovulation. There were statistically significant differences between groups (Table 3).

Table (3): Comparison between three groups as regard to patient's Cancelation rate due to ovulation and cancellation rate

\begin{tabular}{|c|c|c|c|c|c|c|c|}
\hline \multirow{2}{*}{$\mathrm{P}_{\text {Parameters }}$ Groups } & \multicolumn{2}{|c|}{$\begin{array}{c}\text { Group (A) } \\
(\mathbf{n}=\mathbf{1 0 0})\end{array}$} & \multicolumn{2}{|c|}{$\begin{array}{c}\text { Group (B) } \\
(n=100)\end{array}$} & \multicolumn{2}{|c|}{$\begin{array}{c}\text { Group }(\mathbf{C}) \\
(\mathbf{n}=100)\end{array}$} & \multirow{2}{*}{$\begin{array}{c}\mathbf{P} \\
\text { Value }\end{array}$} \\
\hline & No. & $\%$ & No. & $\%$ & No. & $\%$ & \\
\hline \multicolumn{8}{|c|}{ Cancellation rate due to anovulation: } \\
\hline Ovulation & 78 & 78 & 80 & 80 & 68 & 68 & \multirow{2}{*}{$<0.001$} \\
\hline Anovulation & 22 & 22 & 20 & 20 & 32 & 32 & \\
\hline \multicolumn{8}{|l|}{ Cancellation rate: } \\
\hline No & 73 & 73 & 79 & 79 & 68 & 68 & \multirow{3}{*}{$<0.001$} \\
\hline $\begin{array}{l}\text { Cancellation due to } \\
\text { anovulation }\end{array}$ & 22 & 22 & 20 & 20 & 32 & 32 & \\
\hline Cancellation due to OHS & 5 & 5 & 1 & 1 & 0 & 0 & \\
\hline Total & 100 & 100 & 100 & 100 & 100 & 100 & \\
\hline
\end{tabular}




\section{DISCUSSION}

Group (A) show that (8\%) were pregnant while in Group (B) $(7 \%)$ were pregnant and in group (C) (4\%) were pregnant There was no significant difference between groups as regard pregnancy test (clinical and chemical).

Group A had similar ovulation rate with group B with more multiple follicles, more OHSS than group B and C. more cancellation rate than group B.

Group B had similar ovulation rate with group A less in multiple follicles, less OHSS than group $\mathrm{A}$, and less in cancellation rate than group $\mathrm{A}$ and $\mathrm{C}$ and better in endometrial thickness.

Group C more monofollicular growth, less multiple follicles, less multiple pregnancy less OHSS and less coast than group A and B But had less ovulation rate and more in cancellation rate than group $\mathrm{A}$ and $\mathrm{B}$.

Huang et al. (2018) concluded that women with PCOS undergoing stimulated IUI, CC, letrozole and gonadotropins were equally effective and safe. Since multifollicular growth increased the multiple pregnancy rates without increasing the overall live birth rate, ovulation induction would strictly aim for mono-follicular growth. Since letrozole had the highest mono-follicular growth rate, they recommend this drug as the treatment of first.

A randomized trial Clomiphene citrate versus letrozole with gonadotropins in intrauterine insemination cycles Pourali et al. (2017) concluded that the number of matured follicles, cycle cancellation, and abortion were the same in both groups.
Endometrial thickness was higher at the time of human menopausal gonadotropin administration in letrozole group. Chemical and clinical pregnancy rates were much higher in letrozole group. Ovarian hyperstimulation was significantly higher in clomiphene group. Conclusion: Letrozole appears to be a good alternative to clomiphene citrate with fewer side effects which are consistent with our study.

In the study of $Y u$ et al. (2019) endometrial thickness on the day of hCG injection in the letrozole $+\mathrm{HMG}$ group $(8.8 \pm 2.1 \mathrm{~mm})$ was significantly higher than that in the letrozole group $(7.3 \pm 1.6$ $\mathrm{mm})$.. These results were consistent with our study.also the number of follicles with diameters greater than $18 \mathrm{~mm}$ was higher in the letrozole + HMG $(1.21 \pm 0.56)$ and letrozole $(1.14 \pm 0.48)$ groups than that in the CC group $(0.85 \pm 0.36) \quad(\mathrm{P}<0.010)$. These results come in disagreement with our study.

In the study of Abu Hashim et al. (2012) the total number of follicles $\geq 18 \mathrm{~mm}$ during stimulation was statistically significantly greater in the CC group which is consistent with our study.

In the study of Fouda and Sayed et al. (2011) the pregnancy rate per cycle and the cumulative pregnancy rate were significantly higher in extended letrozole group compared with clomiphene citrate group $(18.96 \%$ Vs $11.43 \%$ and $37.73 \%$ Vs $22.86 \%$, respectively) which is in disagreement with our study.

In the study of $\mathrm{Yu}$ et al. (2019) regarding the clinical pregnancy rate, the letrozole group and CC group had a lower rate than the letrozole + HMG group, but 
the statistical results showed no significant difference $(\mathrm{P}=0.052)$ which is consistent with our study.

Choice in infertile women undergoing ovulation induction and IUI.

\section{CONCLUSION}

Ovulation induction and intrauterine insemination (IUI) for PCOS if first lines (lifestyle changes, pharmacotherapy (metformin, clomiphene citrate, letrozole, gonadotropins,) failed. But after complete explanation of the procedure and the success rate and also disscuss the alternatives (laparoscopic surgery (ovarian drilling), and in vitro fertilization) with their risks, coast and success rate and totally respect the patient decision.

There was a successful use of Letrozole plus gonadotrophins in induction of ovulation for PCOS patients undergoing IUI with similar benefits and fewer risks than clomiphene plus gonadotrophins

Also Letrozole plus gonadotrophins had better benefits (more ovulation rate and less cancellation rate and better endometrial thickness) than letrozole alone .but less in monofollicular growth .and more in multiple pregnancy and more coast.

\section{REFERENCES}

1. Abu Hashim H, El Rakhawy M and Abd Elaal I (2012): Randomized comparison of superovulation with letrozole vs. clomiphene citrate in an IUI program for women with recently surgically treated minimal to mild endometriosis. Acta Obstetricia et Gynecologica Scandinavica, 91(3): 338-345.
2. Bordewijk EM, Nahuis $M$ and Costello MF. (2017): Metformin during ovulation induction with gonadotrophins followed by timed intercourse or intrauterine insemination for subfertility associated with polycystic ovary syndrome. Cochrane Database Syst Rev., 24:CD009090.

3. Cohlen B, Bijkerk A and Van der Poel S (2018): IUI: review and systematic assessment of the evidence that supports global recommendations. Human Reproduction Update, 24(3):300-19.

4. Dawson B and Trapp G (2004): Basic \& Clinical Biostatistics 4/E, (4 ${ }^{\text {th }}$ ed.). McGraw-Hill Education / Medical. P. 312.

5. Fouda UM and Sayed AM (2011): Extended letrozole regimen versus clomiphene citrate for superovulation in patients with unexplained infertility undergoing intrauterine insemination: A randomized controlled trial. Reprod Biol Endocrinol., 9: 84-89.

6. Giulia $M$ and José $B$ (2018): Management Options for Infertile Women with Polycystic Ovary Syndrome. US Endocrinology, 14(2):67-72.

7. Guzick DS, Carson SA and Coutifaris C (2013): Efficacy of superovulation and intrauterine insemination in the treatment of infertility. National Cooperative Reproductive Medicine Network. N Engl J Med., 340:177-82.

8. Huang S, Wang R and Li R (2018): Ovulation induction and intrauterine insemination in infertile women with polycystic ovary syndrome; a 
comparison of drugs. European Journal of Obstetrics \& Gynecology and Reproductive Biology, 6: 1-20.

9. Kamath MS, Bhave $P$, Aleyamma TK, Nair R, Chandy A, Mangalaraj AM, Muthukumar $K$ and George $K$ (2010): Predictive factors for pregnancy after intrauterine insemination: A prospective study of factors affecting outcome. J Hum Reprod Sci., 3(3): 129-134.

10. Pourali L, Ayati $S$ and Tavakolizadeh S (2017): Clomiphene citrate versus letrozole with gonadotropins in intrauterine insemination cycles: A randomized trial. Int J Reprod Biomed, 15(1):4954.

11. Rotterdam ESHRE/ASRMSponsored PCOS consensus workshop group (2014): Revised 2003 consensus on diagnostic criteria and long-term health risks related to polycystic ovary syndrome (PCOS). Hum Reprod., 19:41-45.

12. Teede HJ, Misso ML and Costello MF. (2018): International PCOS Network. Recommendations from the international evidence-based guideline for the assessment and management of polycystic ovary syndrome. Fertil Steril., 110:364-79.

13. Yu X, Cao Z, Hou W, Hu W and Yan G (2019): Effects of letrozole combined with human menopausal gonadotrophin in ovarian stimulation for intrauterine insemination cycles. Ann Transl Med., 7(23):771. 
مقارنة بين عقار اللبتروزل منفردا أو اللبتروزل مصحوبا

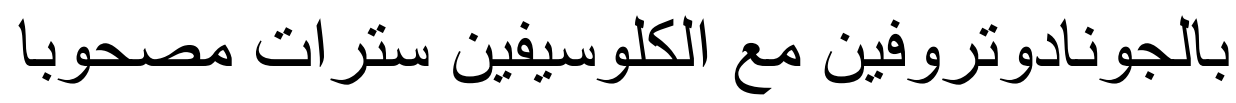
بالجونادوتروفين لتحفيز التبويض في حلات تكبس المبيضين المجهزة للتلقبح الصناعى

أحمد السيد عبدالمقصود, خالد زكريا الشيخة, عادل السيا ابراهيم

قسم أمراض النساء والتوليد، كلية الطب، جامعة الازهر

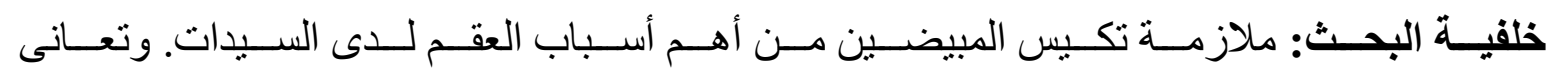

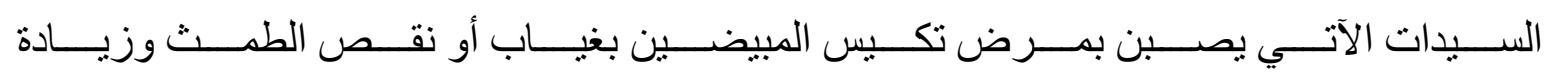

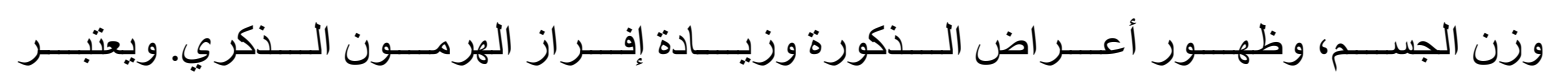

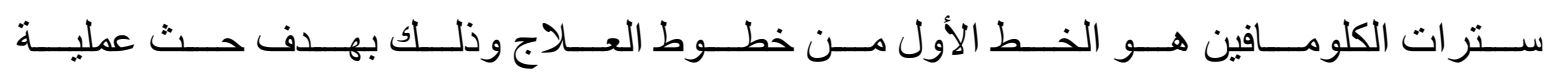

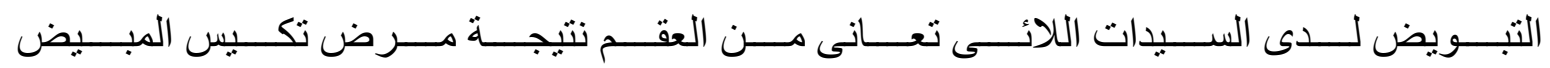

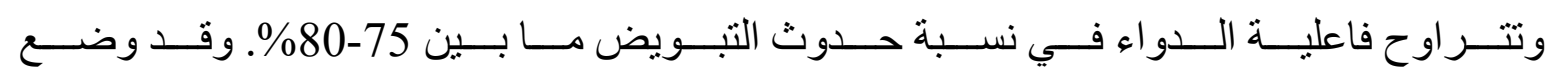

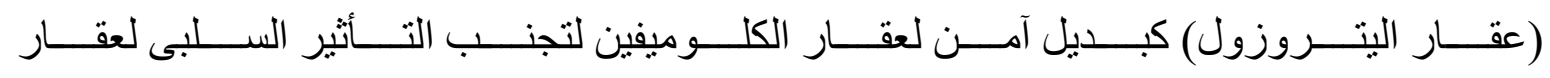

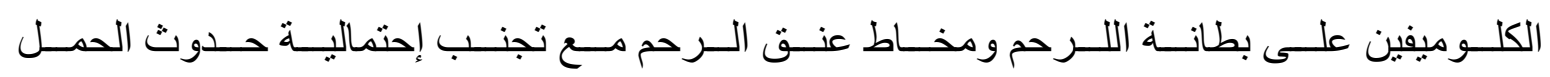

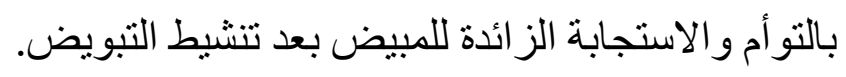

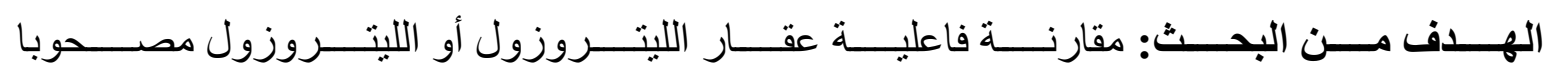

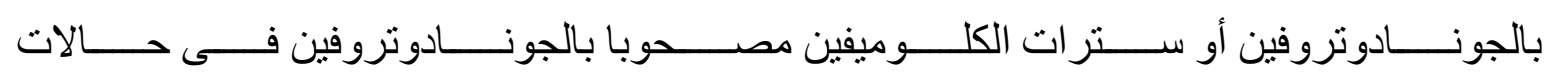

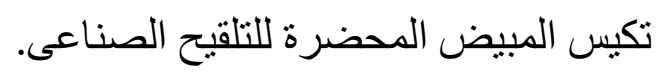

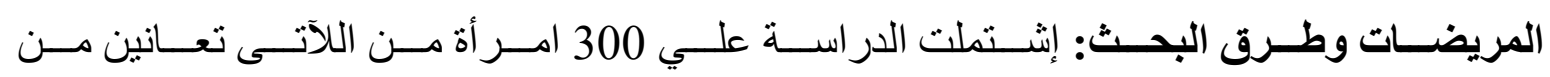

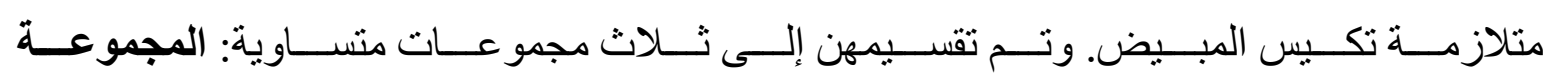

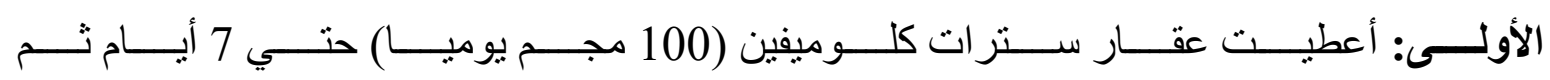

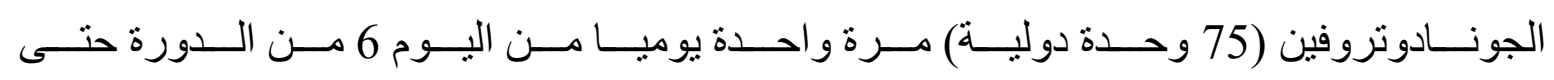

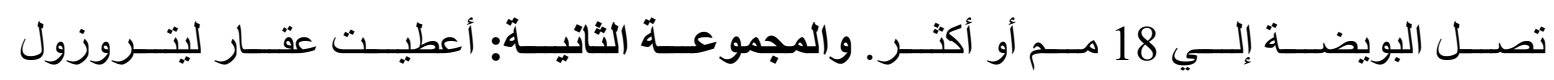

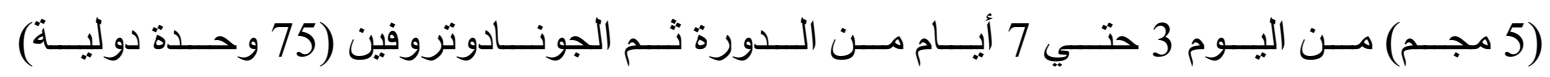

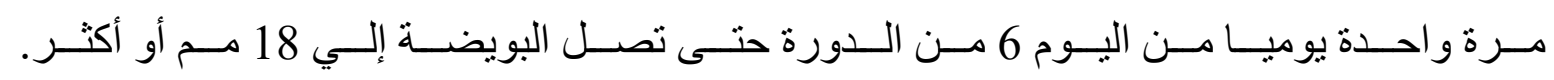




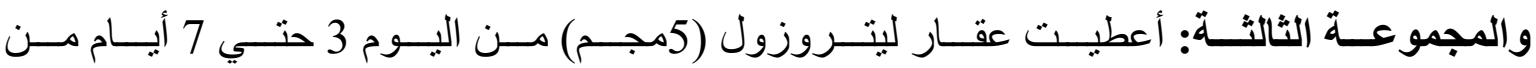

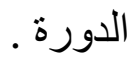

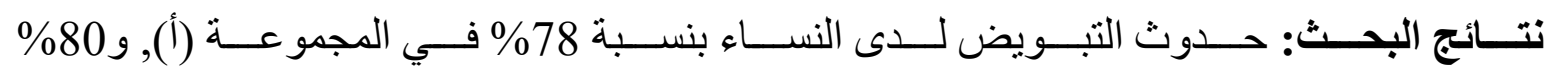

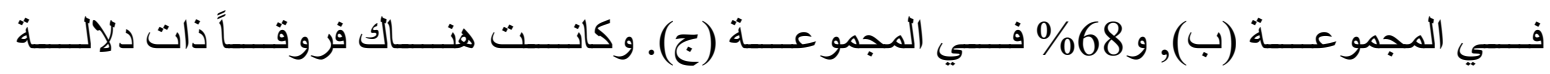

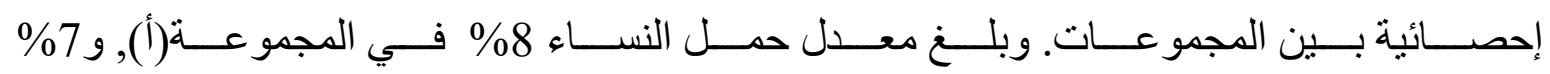

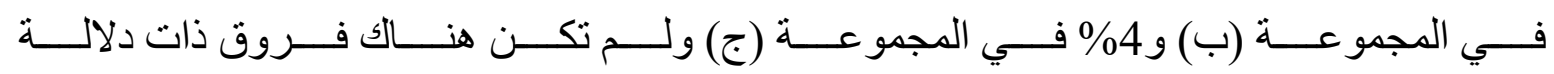

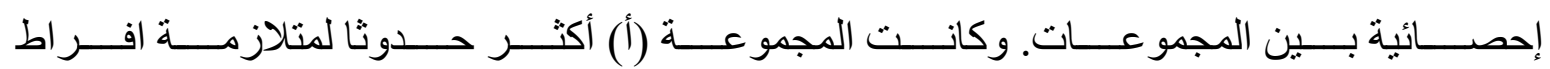

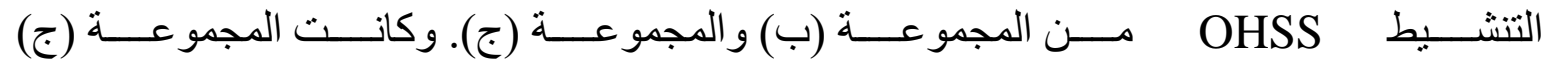

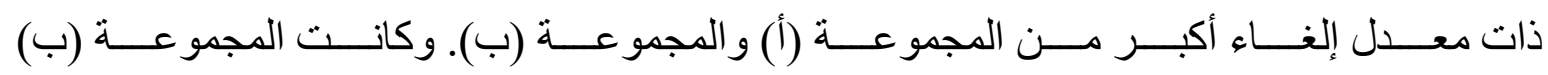

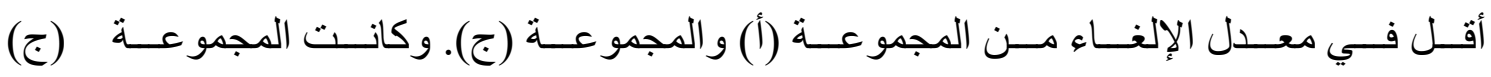
أكثر نموًا أحادي للببويضات.

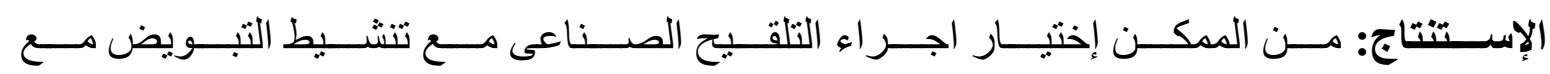
حالات تكيسات المبيضين بعد مو افقة الحالة. 